\title{
ARTÍCULOS
}

\section{CONCEPTOS Y CONTEXTOS PARA UN MARCO DE REFERENCIA SOBRE LA ALFABETIZACIÓN AMBIENTAL EN LA UNIVERSIDAD AUTÓNOMA DE CHIAPAS}

\author{
Elisa Gutiérrez Gordillo ${ }^{1}$ \\ Marisol de Jesús Mancilla Gallardo² \\ Rita Virginia Ramos Castro ${ }^{3}$ \\ Marisol García Cancino ${ }^{4}$ \\ María Minerva López García ${ }^{5}$
}

RESUMEN

El impacto de las ideas y acciones de la especie humana sobre el ecosistema global y los diversos problemas de orden económico, social y político que esta interacción ha generado, han sido objeto de varias reflexiones en distintas disciplinas sociales. De acuerdo a datos proporcionados por la ONU (2016), el daño ocasionado a los diversos ecosistemas en el mundo ha alcanzado ya un nivel crítico y se prevé que la población del planeta alcance una cifra cercana a 9,800 millones de individuos para el año 2050.

En la actualidad, la disponibilidad y el acceso a los recursos necesarios para tener una calidad de vida aceptable es ya un problema en muchas partes del mundo

\footnotetext{
${ }^{1}$ PTC, Facultad de Humanidades C-VI, Universidad Autónoma de Chiapas. 2 PTC, Facultad de Humanidades C-VI, Universidad Autónoma de Chiapas. ${ }^{3}$ PTC, Facultad de Humanidades C-VI, Universidad Autónoma de Chiapas. 4 PTC, Facultad de Humanidades C-VI, Universidad Autónoma de Chiapas. ${ }^{5}$ PTC, Facultad de Humanidades C-VI, Universidad Autónoma de Chiapas.
}

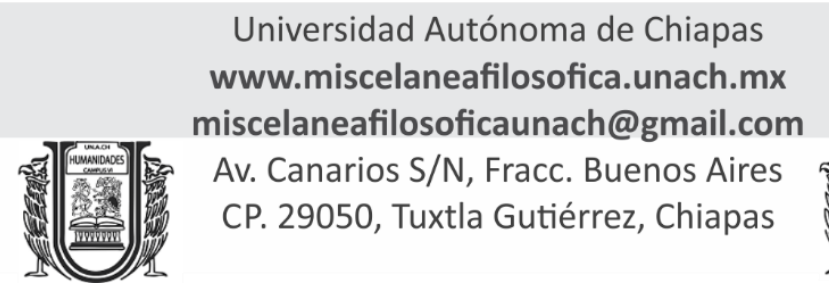


| Cuatrimestral Facultad de Humanidades Campus VI Reserva de Derechos al Uso Exclusivo No.: 04-2018-060814012200-203| ISSN: 2594-1755

Año III | Número 7 | Septiembre- Diciembre 2019

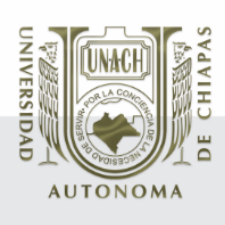

ARTÍCULOS

Wisconsin Center for Environmental Education. (1997). Environmental education in

Wisconsin: are we walking the talk? Wisconsin Center for Environmental

Education, Stevens Point, Wisconsin, USA. 